\title{
POTENSI PEMANFAATAN LIMBAH PLASTIK SEBAGAI ALTERNATIF ELEMEN PENGGANTI DI BANGUNAN CAGAR BUDAYA KOTA SEMARANG (Studi Kasus: Soesman Kantoor)
}

\author{
Frista Kurniasari $^{1)}$, Ferry Hermawan ${ }^{1, *}$, Sudarno $^{2)}$ \\ ${ }^{1)}$ Departemen Teknik Sipil, Fakultas Teknik, Univeristas Diponegoro \\ Jl. Prof. Soedarto, Tembalang, Semarang 50275 \\ ${ }^{2)}$ Departemen Teknik Lingkungan, Fakultas Teknik, Univeristas Diponegoro \\ Jl. Prof. Soedarto, Tembalang, Semarang 50275 \\ ${ }^{*}$ E-mail: ferry.hermawan@ live.undip.ac.id
}

\begin{abstract}
Indonesia as the second largest contributor in global were produced about 9.52 million tons plastic or $14 \%$ of the total waste. The rapid population growth of urban area in Indonesia indirectly encourages various activities that affect the volume of waste. Semarang city were contributing waste in landfills reaches 850,000 tons per day, where 1,000 tons unmanageable. Unsorted garbage has the potential as new materials option in cultural heritage buildings. To elaborate these potential options, this research has been conducted qualitative method as the best approach to answer the research question. This research investigates the stakeholders' perspectives about potential of plastic waste for replacement material of heritage buildings. The results show that there is a lack of data on waste management which is one of the challenges to find out how much volume of plastic waste can be reused. In addition, the principle of building cultural heritage is opposed to the use of plastic waste as an alternative material as a substitute element. In conclusion, plastic waste has a little potential from current waste to be applied on heritage buildings are limited element such as roof, furniture or temporary support of the structural element.
\end{abstract}

Kata kunci : plastic waste, heritage building, alternative material

\section{PENDAHULUAN}

Peningkatan jumlah penduduk di Indonesia yang terjadi setiap tahunnya diiringi dengan peningkatan jumlah sampah yang dihasilkan. Diperkirakan ada sekitar 8 juta ton sampah plastik yang dibuang ke lautan setiap tahun di dunia yang menjadikan Indonesia menjadi negara nomor dua penyumbang sampah plastik terbanyak ke laut setelah Tiongkok (Jambeck et al., 2015). Komposisi limbah padat perkotaan rata-rata di Indonesia terdiri dari $63,17 \%$ sampah organik yang masih terurai, plastik menempati urutan kedua dengan persentase sebesar 13,16 \%, kertas sebesar 8,75 $\%$, kayu sebesar $6,97 \%$, tekstil sebesar $2,03 \%$, logam $1,06 \%$, gelas $0,99 \%$ dan styrofoam 0,07\% (World Bank Group, 2018). Indonesia menyumbang sebanyak 3,22 juta metrik ton (millions of metric tons/MMT) limbah plastik menunjukkan bahwa sampah plastik paling banyak ditemukan di Indonesia, yaitu 25,6 bagian per $100 \mathrm{~m}^{2}$ terumbu karang di lautan (Lamb et al., 2018).

Kota Semarang sebagai salah 
satu kota besar di Indonesia dan sekaligus sebagai ibu kota Jawa Tengah menjadi peringkat nomor enam setelah Kota Bekasi, Jakarta Timur, Makassar, Jakarta Pusat dan Tangerang. Semarang memiliki jumlah penduduk sebanyak 1.658.552 juta jiwa dengan luas wilayah $373,70 \mathrm{~km}^{2}$, jumlah sampah yang ditimbun di Tempat Pembuangan Akhir (TPA) sebanyak 850.000 ton/hari dengan jumlah sampah tidak terkelola sebesar 1.000 ton per hari (Data Sistem Informasi Sampah Nasional Periode 2017-2018). Dengan jumlah yang tergolong besar, perlu adanya penanganan khusus agar tidak terkena dampak negatif yang ditimbulkan oleh sampah tersebut.

Sistem pengelolaan limbah yang efektif berpengaruh terhadap pengurangan limbah plastik sebesar $20 \%$ - 30\% dari penggunaan plastik, dan dapat dimanfaatan menjadi bahan bakar yang diubah menjadi energi sedangkan yang tidak dapat didaur ulang dibuang ke TPA (ZambranaVasquez et al., 2016). Manfaat yang lain dari pemanfaatan limbah plastik selain menjadi bahan bakar, plastik dapat menjadi bahan campuran material untuk memproduksi genteng dengan menggunakan plastik jenis High-Density Polyethylene (HDPE). Plastik dan pasir dikombinasikan menjadi campuran $30 \%$ pasir dan $70 \%$ plastik jenis HDPE sehingga mendapatkan kualitas yang baik (Seghiri et al. 2017). Pengelolaan limbah plastik yang terintegrasi akan memudahkan proses pendauran ulang dan pemanfaatan plastik menjadi barang yang berguna seperti menjadi bahan bakar atau material baru di elemen konstruksi.

Terkait dengan pemanfataan limbah plastik, bangunan cagar budaya di Kota Lama Semarang sedang melakukan proses revitalisasi yang bertujuan untuk memperbaharui dan mengganti bagian-bagian dari bangunan cagar budaya tanpa mengurangi nilai aesthetic dan nilai history nya. Bangunan cagar budaya memiliki material yang unik dan berbeda jika dibandingkan dengan bangunan konvesional. Pemilihan material untuk mengganti bagian pada bangunan cagar budaya membutuhkan anggaran yang besar, untuk itu inovasi pemilihan material dengan bahan dasar plastik dipilih untuk menjadi opsi pada penggantian komponen pada bangunan cagar budaya. Hal tersebut menjadi tujuan dari penelitian ini yaitu untuk memilih jenis plastik yang sesuai dengan karakteristik bangunan cagar budaya karena tidak semua klasifikasi jenis plastik dapat digunakan untuk menjadi alternatif material. Klasifikasi jenis plastik mempunyai sifat dan karakteristik tersendiri agar memenuhi syarat untuk menjadi alternatif bahan material baru.

Di Spanyol, arsitek bernama Ferra Vizoso merenovasi gereja yang mempunyai nilai sejarah pada tahun 1999 hingga 2010 dengan menggunakan plastik jenis Ethylene tetrafluoroethylene (EFTE) untuk mengganti atap gereja yang sudah bolong dan hilang. Plastik dengan jenis EFTE terbukti memiliki daya tahan yang lumayan bagus meski ketebalan 
dan daya tahannya tidak sebagus kaca pada umumnya. Inovasi yang dilakukan dengan menggunakan plastik dapat menghemat anggaran lebih banyak dari rencana sebelumnya (Vizoso, 2017).

Tumpukan limbah plastik terjadi karena kurangnya regulasi, keterkaitan stakeholder dan masyarakat untuk mengurangi plastik. Keterkaitan regulasi dengan pengelolaan limbah plastik di San Fransisco, Flanders dan Jepang juga terkait dengan kebijakan limbah plastik. Perlunya kebijakan regulasi pemerintah, keterlibatan stakeholder dan regulasi lingkungan yang akan menjadi transisi dari pembuangan akhir di TPA ke Program Zero Waste untuk mencapai manajemen limbah yang berkelanjutan (Silva et al., 2017). Kurangnya manajemen limbah di konstruksi menyebabkan pembuangan limbah di 4227 proyek konstruksi besar di Hong Kong, terjadi karena perbedaan persepsi tentang manajemen limbah konstruksi antara sektor publik dan sektor swasta yang saling bertentangan dengan regulasi ( $\mathrm{Lu}$ et al., 2016).

Plastik tidak dapat berkurang jika tidak dilakukan kerja sama secara bersamaan. Regulasi yang tepat berkontribusi untuk mengelola timbunan sampah dan pemikiran serta pertimbangan stakeholder untuk memilah sampah pasca konstruksi berpengaruh banyak. Jika regulasi dan stakeholder berjalan dengan baik, maka inisiatif warga dalam menyortir sampah rumah tangga adalah aspek penyempurnaan dari pengelolaan limbah plastik yang terintegrasi.

Faktor masyarakat, regulasi dan stakeholder yang menjadi tantangan pengelolaan limbah plastik saat ini dapat diselesaikan dengan wawasan dan pemahaman stakeholder terhadap regulasi institusional. Pemahaman stakeholder terhadap manajemen limbah sangat diperlukan karena jika stakeholder tidak memberikan perhatiannya pada masalah pembuangan limbah di konstruksi, maka limbah tersebut akan berakhir di TPA dan tidak dapat dilakukan daur ulang. Antisipasi yang dapat dilakukan oleh pemerintah misalnya dengan menetapkan regulasi yang mengikat stakeholder untuk turut serta dan bertanggung jawab terhadap pembuangan limbah di konstruksi. Kerja sama terhadap permasalahan sampah akan berjalan secara optimal jika antara stakeholder, warga lokal dan komunitas lokal bergerak bersamaan. (MacRae and Rodic, 2015)

Tantangan pengelolaan sampah dapat dilakukan secara terintegrasi jika stakeholder, masyarakat lokal dan komunitas lokal bekerja sama untuk memilah sampah rumah tangganya sehingga dapat terlihat seberapa banyak volume jenis plastik yang paling banyak dikonsumsi sehingga kegiatan daur ulang lebih mudah dilakukan. Pada penelitian ini, faktorfaktor yang menghambat pengelolaan sampah akan diobservasi untuk mewujudkan pengelolaan sampah yang terintegrasi dalam bentuk kerangka kerja agar timbunan sampah plastik berkurang.

Limbah sampah plastik 


\begin{abstract}
mempunyai potensi untuk dimanfaatkan kembali, selain mengurangi jumlah sampah plastik hal ini memberikan alternatif elemen pengganti baru untuk bangunan cagar budaya dengan menggunakan jenis sampah plastik yang sesuai pada kondisi bangunan gedung. Bagaimana potensi sampah plastik yang dapat dimanfaatkan menjadi alternatif material baru di bangunan cagar budaya menjadi pertanyaan penelitian ini yang selanjunya akan di implementasikan ke dalam kerangka kerja (framework) sebagai acuan pemilihan jenis plastik yang sesuai untuk menjadi alternatif bahan material baru pada bangunan cagar budaya di Kota Semarang.
\end{abstract}

\section{METODE PENELITIAN}

Lokasi penelitian studi kasus pada kawasan kota lama Semarang tepat nya di Soesman Kantoor yang terletak di Jl. Kepodang No.15, Purwodinatan, Semarang Tengah, Kota Semarang. Studi kasus dengan pendekatan kualitatif adalah metode terbaik untuk jenis pertanyaan penelitian ini, metode kualitatif adalah pendekatan terbaik untuk jenis pertanyaan penelitian ini, yang digunakan peneliti untuk memahami perspektif orang atau kelompok dan untuk mengembangkan dan merevisi hipotesis penelitian. Walaupun cakupan atau wilayah kajiannya sempit, secara substantif penelitian studi kasus sangat mendalam, dan diharapkan dari pemahaman tersebut dapat diperoleh sebuah konsep atau teori tertentu untuk pengembangan ilmu pengetahuan
(Rahardjo, 2017).

Pengumpulan data berupa data primer data sekunder. Strategi pengumpulan data primer diperoleh dengan observasi, wawancara, dan Forum Group Discussion (FGD). Observasi digunakan pada obyek studi kasus yaitu Soesman Kantoor dan Responden yang terlibat dalam penelitian ini terdiri dari 7 narasumber antara lain dari instansi satu anggota BPK2L (Badan Pengelola kawasan Kota Lama Semarang), dua anggota TACB (Tenaga Ahli Cagar Budaya), satu Arsitek peneliti Bangunan Kota Lama, dua UPTD (Unit Pelaksana Teknis Dinas) Kota Semarang, satu DLH (Dinas Lingkungan Hidup) dan satu dosen bidang Teknik Kimia. FGD dilakukan dengan stakeholder untuk melakukan diskusi tentang persepsi masing-masing stakeholder dalam upaya perbaikan bangunan cagar budaya di Kawasan Kota Lama Semarang. Pengumpulan data sekunder berupa kajian teori dari literatur, jurnal, buku, majalah, artiel, koran, dokumen, regulasi dan dokumen yang berkaitan dengan penelitian berupa data pengelolaan sampah dan laporan survey revitalisasi Gedung Soesman Kantoor di Kawasan Kota Lama Semarang. Validitas data diperoleh dengan metode triangulasi dari sumber data yang saling terkait dari hasil FGD, regulasi dan survey lapangan.

\section{HASIL DAN PEMBAHASAN}

Pengelolaan Sampah di Lokasi Studi

Data yang digunakan merupakan hasil dari survey yang dilaksanakan oleh petugas UPTD Wilayah 1 Kota 
Semarang untuk melengkapi data survey yang dilakukan oleh DLH. Data sampah diambil di sekitar wilayah lokasi penelitian yaitu kawasan kota lama, TPS Kolonel Soegiono menjadi lokasi pengambilan data sampah penelitian ini karena masuk ke lingkup
UPTD Wilayah 1. Pengambilan data dilakukan dengan mengisi kuisioner yang diberikan ke perosok Sumber Nikmat di Jl. Kolonel Soegiono. Data sampah di TPS Kolonel Soegiono tahun 2017 dapat dilihat pada Tabel 1 berikut:

Tabel 1. Data Sampah TPS Kolonel Soegiono Tahun 2017

\begin{tabular}{cccccccc}
\hline Responden & $\begin{array}{c}\text { Tahun } \\
\text { Berdiri }\end{array}$ & \multicolumn{5}{c}{ Rincian Jumlah Sampah (kg/th) } & \multirow{2}{*}{$\begin{array}{c}\text { Jumlah } \\
\text { Total }\end{array}$} \\
\cline { 3 - 6 } & & Logam & Kertas & Plastik & Aki & Lainnya & \\
\hline R1S & 2003 & 6.000 & 2.400 .000 & 2.400 .000 & 1.200 & 60.000 & 4.867 .200 \\
R2D & 2004 & 3.600 & 600.000 & 600.000 & 600 & 48.000 & 1.252 .000 \\
R3A & 2008 & 3.600 & 480.000 & 480.000 & 600 & 48.000 & 1.012 .200 \\
R4B & 2008 & 3.600 & 600.000 & 600.000 & 1.200 & 54.000 & 1.258 .800 \\
R5A & 2004 & 6.000 & 540.000 & 540.000 & 1.200 & 42.000 & 1.129 .200 \\
R6M & 2003 & 6.000 & 1.800 .000 & 1.800 .000 & 1.080 & 54.000 & 3.661 .080 \\
\hline
\end{tabular}

Pada tabel 1. jumlah sampah per tahun yang paling banyak di kumpulkan oleh perosok TPS Kolonel Soegiono adalah kertas dan plastik. Sampah kertas yang dikumpulkan berupa koran dan sampah plastik berupa botol. Setelah perosok mengumpulkan dan mengklasifikasikan jenis sampah yang didapat maka proses pemilahan dilakukan oleh perosok untuk dijual kembali. Pada gambar 1. (a) dan (b) terlihat perosok mengelompokan botol plastik berdasarkan warna agar memudahkan proses jual beli limbah plastik.

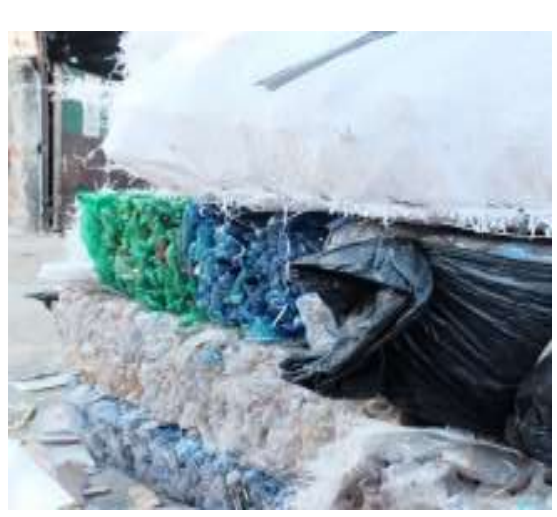

(a)

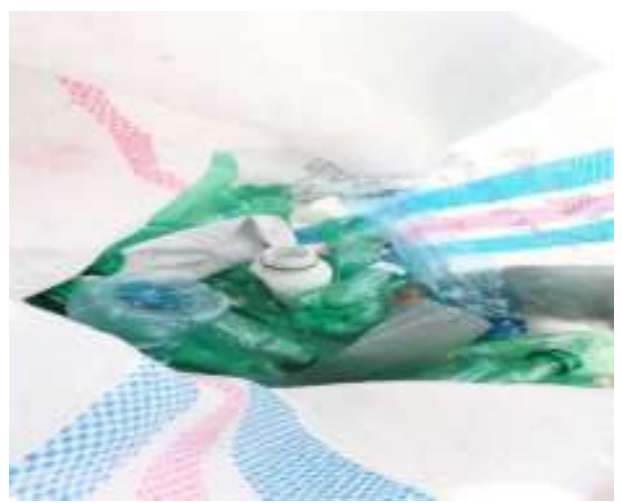

(b)

Gambar 1. (a) Pengelompokan botol plastik; (b) Pengelompokan botol plastik

Pada Gambar 1 (a) dan (b) Kolonel Soegiono memilah sampah perosok Ibu S dan Bp. A di TPS kardus dan botol plastik, botol plastik 
dikumpulkan berdasarkan warna hijau, biru dan bening yang biasanya dibeli untuk didaur ulang kembali. Perosok memiliki peran yang sangat penting dalam mengurangi masalah lingkungan yang disebabkan oleh sampah plastik yang kemudian memberikan fakta bahwa sampah dapat diolah menjadi berbagai produk, maka perlunya melakukan pengelolaan sampah secara bijak dengan melibatkan seluruh masyarakat termasuk perosok.

Pemilahan sampah yang dapat didaur ulang kembali hanya dilakukan di TPS sebelum di buang ke TPA karena sampah yang sudah masuk ke TPA tidak dapat dimanfaatkan kembali. Jumlah sampah yang masuk ke TPA Jatibarang per hari mencapai 1.000 ton, jumlah tersebut didapat dari data timbangan truk sampah sebelum masuk ke TPA Jatibarang. Adapun komposisi sampah di TPA Jatibarang dapat dilihat pada Tabel 2 sebagai berikut:

Tabel 2. Komposisi Sampah TPA Jatibarang

\begin{tabular}{llc}
\hline No. & \multicolumn{1}{c}{ Tipe Material } & Komposisi \\
\hline 1 & Material yang dapat terurai (organik) & $65,27 \%$ \\
\hline 2 & Karton, kardus, kertas, tetrapak & $3,58 \%$ \\
\hline 3 & Plastik (3D, 2D, film, plastik warna,karung beras) & $20,11 \%$ \\
\hline 4 & Tekstil (kain, karung goni, pembalut, bahan kulit) & $8,45 \%$ \\
\hline 5 & Karet (ban, karet, busa) & $0,40 \%$ \\
\hline 6 & Metal (alumunium, besi, kaleng, aerosol) & $0,12 \%$ \\
\hline 7 & Inert (kaca, puing, pvc, asbes) & $2,06 \%$ \\
\hline 8 & B3 (baterai, limbah, medis, elektronik) & $0,01 \%$ \\
\hline & & $100 \%$ \\
\hline
\end{tabular}

Komposisi sampah di TPA Jatibarang pada Tabel 2. menghasilkan sebesar $65,27 \%$ sampah organik yang dapat terurai dengan sendirinya dan $34,73 \%$ sampah organik yang tidak dapat terurai yang tidak dapat dimanfaatkan kembali, 20,11\% diantaranya adalah sampah plastik. Sampah plastik yang dibuang di TPA antara lain plastik 3D, 2D, plastik dan karung beras, jika diamati plastik botol tidak ada di TPA karena sudah selesai dipilah di TPS.
Berdasarkan data sampah pada tabel 3 diperoleh fakta bahwa data sampah yang dilakukan dengan metode survey dan kuisioner oleh petugas UPTD Wilayah 1 di TPS yang tersebar di Kota Semarang tidak akurat, hal itu didasari oleh sulitnya angka real di lapangan terkait dengan berapa jumlah sampah yang masuk dan berapa jumlah sampah yang sudah dipilah oleh perosok di setiap TPS. 
Tantangan Pengelolaan Sampah di Kota Semarang

Pengelolaan sampah plastik yang sudah melalui tahapan pemilahan akan memudahkan proses daur ulang sampah, karena jumlah sampah plastik per kilogram yang dijual oleh perosok dapat memberi gambaran seberapa banyak sampah plastik yang dapat dimanfaatkan menjadi barang yang mempunyai nilai jual tinggi. Akan tetapi, pemilahan sampah yang dilakukan oleh perosok setiap hari nya belum tentu dapat mengurangi jumlah timbunan sampah karena kurang nya keikutsertaan masyarakat dalam memilah sampah rumah tangga nya sebelum di buang ke TPS serta tidak akurat nya data sampah yang tersedia di lapangan, hal itu menjadi salah satu tantangan dalam pengelolaan dan pemanfaatan limbah plastik. Limbah plastik mempunyai sisi positif dan negatif jika tidak dilakukan secara bersamaan, sisi positif dari limbah plastik diketahui dapat mengubah limbah plastik menjadi produk baru seperti kerajinan tangan dan menjadi alternatif material baru di konstruksi bangunan dan konstruksi jalan sedangkan sisi negatif nya yaitu pencemaran lingkungan yang akan berpengaruh ke polusi udara dan kesehatan masyarakat. Pemanfaatan limbah plastik tersebut pada umumnya di aplikasikan ke bangunan gedung biasa sehingga potensi pemanfaatan berada dalam ruang lingkup yang luas, sedangkan fokus penelitian ini berada pada ruang lingkup yang sempit, dimana bangunan cagar budaya dimana bangunan tersebut merupakan bangunan yang dilestarikan dan dilindungi oleh pemerintah karena mempunyai nilai sejarah yang tinggi. Pemanfaatan limbah plastik di bangunan cagar budaya akan berbenturan dengan prinsip-prinsip yang sudah dijelaskan pada Background 2.5, prinsip-prinsip tersebut juga di atur dalam Peraturan Daerah Khusus Ibukota Jakarta No.9 Tahun 1999 Pasal 15 ayat (3) tentang keaslian bentuk, bahan, penyajian dan tata letak dengan memperhatikan nilai sejarah, ilmu pengetahuan dan kebudayaan.

Berdasarkan hasil wawancara yang dilakukan kepada tiga narasumber diperoleh hasil bahwa data sampah di Kota Semarang adalah angka estimasi yang digunakan untuk memudahkan pelaporan ke Kementerian Lingkungan Hidup dan Kehutanan. Adapun kendala pengumpulan data sampah antara lain (1) pengumpulan data tidak sebanding dengan tenaga kerja yang melakukan survey, (2) tidak mendukungnya software khusus perhitungan data sampah di TPA dan (3) Perosok di TPS tidak melakukan pencatatan jumlah sampah yang masuk dan jumlah sampah yang dipilah.

Hal tersebut yang menjadi hambatan dalam pengumpulan data pengelolaan sampah maka estimasi perhitungan digunakan untuk memudahkan hitungan kasar dari berapa jumlah limbah plastik yang sudah dikelola dan dipilah. Selain sulitnya mendapatkan data sampah yang kongkrit, pada saat proses wawancara didapat fakta lain 
tantangan dalam pengelolaan sampah. Tantangan pengelolaan sampah yang memiliki peran besar untuk membatu mengelola dan memilah limbah sampah nya ada pada masyarakat dan stakeholder karena kurangnya kesadaran untuk memilah limbah sampah nya masing-masing sebelum dibawa ke TPS.

\section{Tantangan Pemanfaatan Plastik di Bangunan Cagar budaya}

Bangunan cagar budaya merupakan bangunan yang mendapatkan perlakuan khusus pada proses revitalisasi karena harus tetap menjaga otentisitas dari bangunan tersebut. Fakta bahwa pemanfaatan plastik yang akan di aplikasikan di bangunan cagar budaya mengalami tantangan karena tidak sesuai dengan prinsip-prinsip konservasi. Maka dari itu, penulis melalukan wawancara untuk mengetahui sejauh mana potensi plastik dapat digunakan sebagai alternatif material pengganti di bangunan cagar budaya tetapi tidak berbenturan dengan prinsip-prinsip konservasi.

Berdasarkan hasil wawancara didapatkan hasil bahwa plastik mempunyai potensi untuk dimanfaatkan di bangunan cagar budaya selama memperhatikan beberapa aspek berikut:

a. Pemanfaatan plastik di bangunan cagar budaya tidak mempengaruhi penampilan bangunan.

b. Perubahan di bangunan cagar budaya tidak mengubah fasade, dan di izinkan mengubah fungsi bangunan. c. Memahami karakteristik dari plastik yang akan dijadikan ke elemen bangunan cagar budaya dan mengetahui pendekatan apa yang sesuai.

Pemanfaatan limbah plastik di bangunan cagar budaya mempunyai potensi yang tidak besar tapi mungkin untuk dilakukan selama memperhatikan prinsip-prinsip konservasi dan tidak mempengaruhi penampilan bangunan cagar budaya. Akan tetapi, penggunaan plastik tidak bisa diaplikasikan ke semua elemen bangunan karena tidak semua jenis plastik mempunyai karakteristik yang sesuai dengan karakteristik elemen bangunan. Maka dari itu akan dijelaskan melalui wawancara kepada narasumber terkait rekomendasi elemen bangunan yang dapat dijadikan alternatif pengganti dengan limbah plastik.

Rekomendasi yang diberikan oleh pakar konservasi mengacu pada elemen penutup atap, dinding pembatas, furniture dan genteng pada bangunan cagar budaya. Elemen tersebut dipilih karena tidak mempengaruhi penampilan bangunan dan tidak bertentangan dengan prinsipprinsip konservasi hal ini menjadi salah satu fakta dari penelitian ini. Fakta tersebut didukung dengan perspektif dari diskusi pada saat FGD mengungkapkan bahwa potensi pemanfaatan limbah plastik di kabel ME, secara tidak langsung pernyataan tersebut memiliki kesamaan untuk tidak merubah penampilan dari bangunan cagar budaya. Akan tetapi jika dilihat dari segi material kimia 
plastik jika plastik di aplikasikan ke kabel ME maka akan terjadi kesulitan saat pengaplikasian karena ada material kimia yang tidak sesuai dengan karateristik plastik.

Potensi pemanfaatan plastik sebagai elemen pengganti penutup atap, struktur sementara, genteng, furniture dan dinding pembatas ruangan yang di rekomendasikan oleh pakar konservasi. Maka pada saat melakukan pemilihan jenis plastik yang cocok dengan karakteristik bangunan cagar budaya dapat menyesuaikan dengan physical property plastik kemudian dilakukan uji laboratorium untuk mendapatkan tingkat keakuratan yang tinggi.

Kerangka Konsep Pemanfaatan Limbah Plastik Sebagai Alternatif Elemen Pengganti di Bangunan Cagar budaya

Berdasarkan analisis yang telah penulis jelaskan maka diperoleh kerangka kerja hasil dari analisis tersebut yang dapat dilihat pada Gambar 2. Berikut

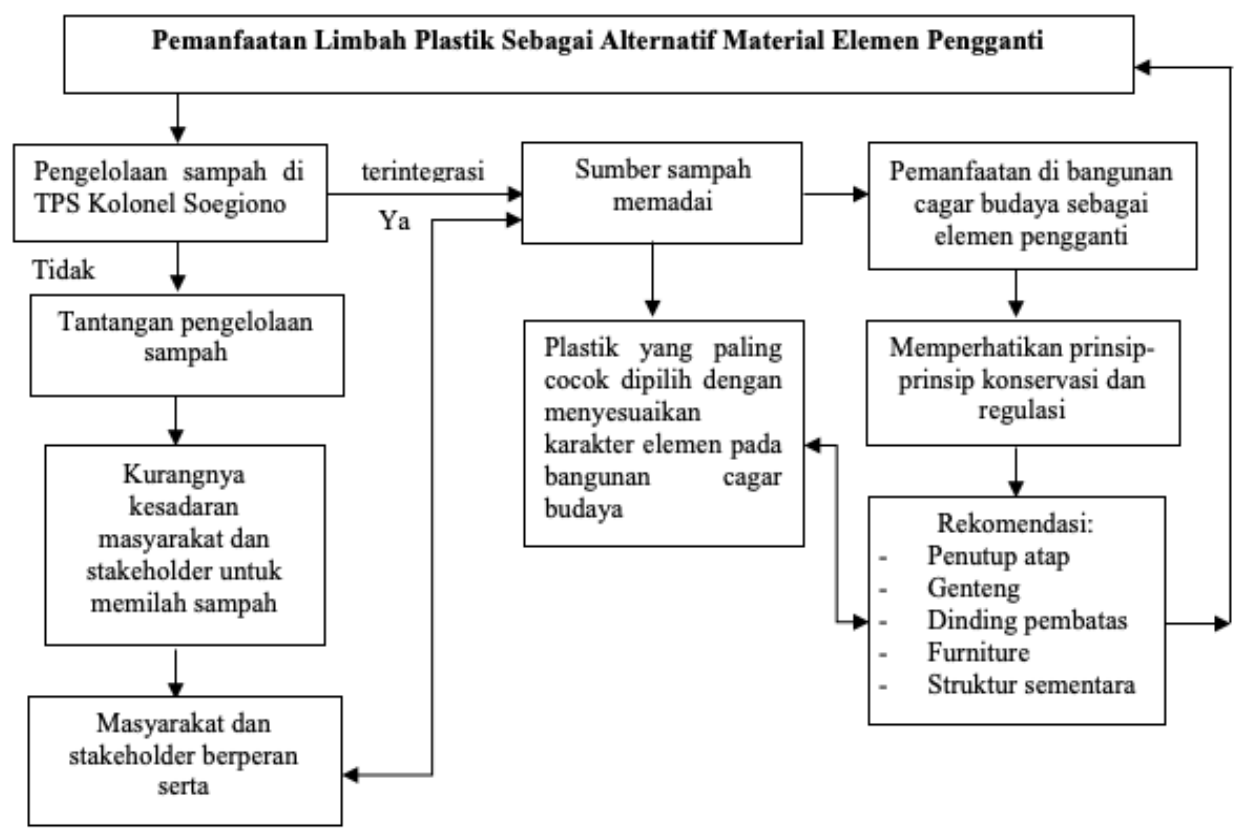

Gambar 2. Kerangka Konsep Pemanfaatan Limbah Plastik Sebagai Alternatif Elemen Pengganti di Bangunan Cagar Budaya

Kerangka konsep diatas dapat digunakan untuk melakukan pemanfaatan limbah plastik di bangunan cagar budaya sebagai elemen pengganti. Pengelolaan sampah yang terintegrasi di TPS Kolonel Soegiono akan memberikan volume sumber plastik yang dapat dimanfaatkan di bangunan cagar budaya. Potensi dari sumber plastik tersebut dapat dijadikan alternatif elemen pengganti jika memperhatikan prinsip-prinsip konservasi dan regulasi. Pada bangunan cagar budaya tidak semua elemen dapat diganti dengan bahan material yang baru karena 
bertentangan dengan prinsip-prinsip konservasi, maka dari itu elemen pengganti yang direkomendasikan hanya penutup atap, genteng, dinding pembatas, furniture dan struktur sementara karena jika plastik menjadi alternatif material pengganti tidak akan menghilangkan otentisitas dari bangunan tersebut. Pemilihan plastik yang cocok dengan elemen pengganti bangunan cagar budaya juga harus menyesuaikan dengan karakteristik elemen dan plastik dari sisi titik leleh, kuat lentur, daya serap air, suhu maksimal agar mendapatkan jenis plastik yang cocok serta dapat diuji kekuatannya di laboratorium pada penelitian selanjutnya. Jika pengelolaan sampah tidak terintegrasi maka perlunya kesadaran masyarakat dan stakeholder untuk memilah sampahnya agar didapat sumber plastik yang memadai untuk dimanfaatkan.

\section{SIMPULAN}

Beberapa faktor yang mempengaruhi pengelolaan sampah di Kota Semarang antara lain kurangnya kesadaran masyarakat dan stakeholder untuk mengelola sampah sebelum dibuang ke TPS, sedangkan yang berkontribusi dalam memilah sampah adalah perosok dan pemulung karena timbunan sampah sudah berkurang sebelum dibuang ke TPS dan kurangnya software pendukung untuk menganalisa berapa jumlah kongkrit dari sampah yang sudah dipilah. Pemilahan sampah yang dilakukan di TPS akan memudahkan proses pemanfaatan limbah plastik karena adanya volume sampah pasti. Limbah plastik berpotensi diterapkan di konstruksi jalan, konstruksi bangunan, menjadi bahan bakar maupun kerajinan tangan asalkan proses pengelolaan dan pemilahan sampah berlangsung dengan baik.

Limbah plastik mempunyai potensi yang tidak besar untuk diterapkan di bangunan cagar budaya karena terbentur dengan prinsip-prinsip konservasi. Pemanfaatan plastik menjadi elemen pengganti diperkenankan selama menjaga otentisitas dan prinsip-prinsip bangunan cagar budaya. Pemilihan jenis plastik sebagai alternatif elemen pengganti di bangunan cagar budaya dilakukan dengan memperhatikan physical property dari jenis plastik dan karakteristik elemen bangunan yang akan diganti dengan limbah plastik. Kesamaan karakteristik plastik dan elemen bangunan berperan penting dalam pemanfaatan plastik tersebut.

\section{UCAPAN TERIMA KASIH}

Terima kasih kepada Dinas Tata Ruang, Pemerintah Kota Semarang, Prof. Nani Y. (Prodi Perencanaan Wilayah dan Kota, Universitas Diponegoro), Ir. Tjahyono (BPK2L Kota Semarang), Ir. Satrio Nugroho (Departemen Teknik Arsitektur, Universitas Diponegoro), Segenap Staf dan Assisten Laboratorium Manajemen Konstruksi Departemen Teknik Sipil, Universitas Diponegoro dan para Narasumber yang telah membantu penelitian ini.

\section{DAFTAR PUSTAKA}

Jambeck, J. R., Geyer, R., Wilcox, C., 
Siegler, T. R., Perryman, M., Andrady, A., Law, K. L., 2015, Plastic waste inputs from land into the ocean. 5. ScienceMag.com (Diakses Januari 2019)

Lamb, J. B., Willis, B. L., Fiorenza, E. A., Couch, C. S., Howard, R., Rader, D. N., Harvell, C. D., 2018, Plastic waste associated with disease on coral reefs. Science, 359(6374), 460-462

Lu, W., Chen, X., Ho, D.C.W., Wang, H., 2016, Analysis of the construction waste management performance in Hong Kong: the public and private sectors compared using big data. J. Clean. Prod. 112, 521-531.

MacRae, G., Rodic, L., 2015, The weak link in waste management in tropical Asia? Solid waste collection in Bali. Habitat Int. 50, 310-316.

Rahardjo, Mudjia, 2017, Studi kasus dalam penelitian kualitatif: konsep dan prosedurnya. Researh Repository Universitas Islam Negeri Maulana Malik Ibrahin Malang. Teaching Resources.

Republik Indonesia, 1999, Peraturan Daerah Khusus Ibukota Jakarta No.9 Tahun 1999

Seghiri, M., Boutoutaou, D., Kriker, A., \& Hachani, M. I., 2017,
The Possibility of Making a Composite Material from Waste Plastic. Energy Procedia, 119, 163-169.

Silva, A., Rosano, M., Stocker, L., Gorissen, L., 2017, From waste to sustainable materials management: Three case studies of the transition journey. Waste Manag. 61, 547-557.

Sistem Informasi Pengelolaan Sampah Nasional.

http://sispn.menlhk.go.id.

(Diakses 5 Maret 2019)

Vizoso, Ferra, 2017, Restoration of the old Church of Corbera d'Ebre, Terra Alta, Tarragona. http;//www.divisiare.com.

(Diakses 21 Maret 2019)

World Bank Group, 2018, Kementerian Koordinator Bidang Kemaritiman., Embassy of Denmark., Royal Norwegian Embassy. Laporan Sintesis: Hotspot Sampah Laut Indonesia.

Zambrana-Vasquez, D., ZabalzaBribián, I., Jáñez, A., \& Aranda-Usón, A., 2016, Analysis of the environmental performance of life-cycle building waste management strategies in tertiary buildings. Journal of Cleaner Production, 130, 143-154. 